\title{
The 2007 Solar D House
}

\author{
M. Garrison
}

School of Architecture, The University of Texas at Austin, USA

\section{Abstract}

The Solar Decathlon is an international initiative and University competition sponsored by the U.S. Department of Energy, designed to stimulate research, industry and education to advance renewable energy technologies, with a specific focus on building-integrated photovoltaics. Now entering its fourth cycle, the Decathlon provides a unique opportunity to envision, fabricate and test the possibilities of highly efficient modern dwellings. Our team of architecture and engineering faculty and students under the direction of Professor Michael Garrison, Professor Samantha Randall, Atila Novoselac, and Russell Krepart has constructed a completely stand-alone solar-powered home that serves as a catalyst for change, leading the residential housing industry toward more sustainable practices while addressing the need for well designed, appropriately diverse, economically viable, and environmentally responsible housing. Through use of solar power, this project offers homeowners the means to directly participate in the energy economy, moving from energy consumers to energy producers.

The Solar Decathlon completion occurs every two years and is run by the National Renewable Energy Lab, which requires a portable structure of a fairly modest scale, with a dual prescription for both exhibition and inhabitation. The Program calls for the design to appeal to the average lifestyle of the general public -- the solar decathlon house is designed to support all the power needs of a typical household, including lighting, cooking, heating and cooling, telecommunications, and with enough energy remaining to charge an electric vehicle for getting around. The Competition requires the construction of the home "offsite," a maximum dwelling footprint of 800 square feet, suitable for two people and mobile, so that it can be transported for a temporary exhibition "village," on the National Mall and installed in four days, occupied during the competition and then subsequently removed and shipped back to Austin. The University of Texas has participated in the competitions in 2002, 2005 and 2007.

To meet these needs, the 2007 Texas Solar D House, called the BLOOMHouse because it represents the "seed" of new ideas, the team developed a prefabricated $6.6 \mathrm{~kW}$ stand-alone solar-powered modular house that sits lightly on the land and forms the superstructure for photovoltaic technologies and a sustainable approach to the building envelope. The prefabricated house can be adapted to a specific site and modified for the needs of a different site within a different climatic zone, and client context. Affordability is also a factor, as the house meets the target of $\$ 0.10 / \mathrm{kWh}$ to power in the year 2015 , recognizing that consumers look to the Solar Decathlon entries for ideas of how to integrate renewable energy technologies into their own homes this house will serve as a working example to homeowners.

Keywords: photovoltaics, solar design. 


\section{Design}

The rules for the 2007 Solar Decathlon competition added "market viability" as another part of the contests. Jurors assessed how well and easily the house could be brought to market and also whether the house had market appeal, is livable, has a flexible layout and is affordable.

To respond to this requirement for a broad-based market appeal the 2007 UT Solar D team adopted an interdisciplinary approach. Although the student-led team remained under the direction of the School of Architecture, it also included a diverse partnership of faculty leads from different disciplines from Engineering to Marketing to Interiors, and with an Advisory Council of business and industry professionals. The team has developed a $6.6 \mathrm{~kW} \mathrm{PV}$ array with a skin-based design strategy that responds to orientation, climate and culture. The 14-footwide x 50-foot-long streamlined, singlewide design was determined by shipping dimensions and speed of construction.

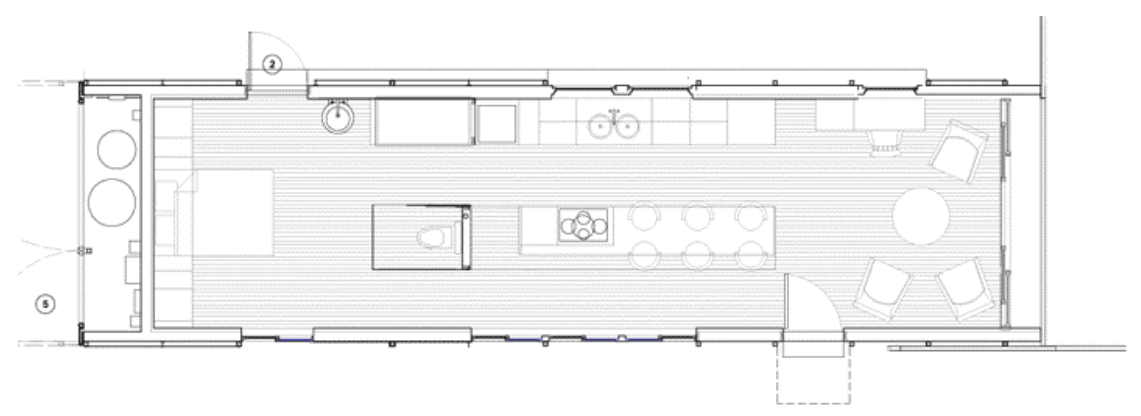

Figure 1: Open floor plan of the BLOOMhouse (drawing by Crystal Bryant).

The BLOOMhouse is constructed of 6" thick Structurally Insulated Panels (SIPs) with an R-24 insulation value that reduces heating and cooling costs throughout the life of the home. Metal-faced SIPs perform structurally as a stress skin panel, and act as a thermal and moisture barrier. Because the house is made using lightweight, metal-faced SIPs as a single airtight envelope, the infiltration load was reduced to less than one half of air change per hour and an Energy Recovery Ventilator (ERV) was incorporated into the house to ensure adequate amounts of fresh air.

The photovoltaic panels, together with a steel carriage form a butterfly roofshading device. The PV panels are mounted in racks of 5 over the flat roof to speed up on-site deployment time. These racks are supported on vertical steel frames on the north and south façade of the house. The steel frames are called "moment frames" which pick up lateral forces on the long sides of the house and allow for the elimination of interior sheer walls to achieve an open free flowing spacious plan arrangement. The openness of the design simultaneously facilitates daylighting, effective cross ventilation and a fluid indoor/outdoor relationship with the outdoor decks that surround the house. As a consequence a house of a fairly modest scale appears large and spacious. 


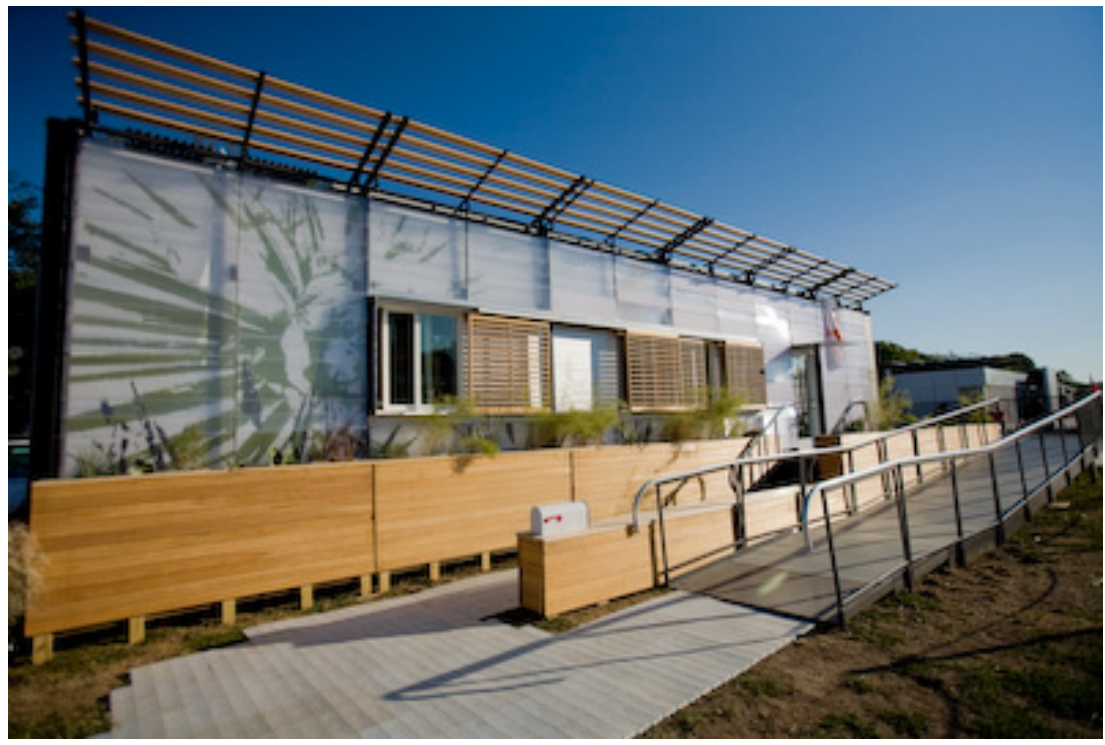

Figure 2: $\quad$ South Elevation of the BLOOMhouse (photo by Alex Miller).
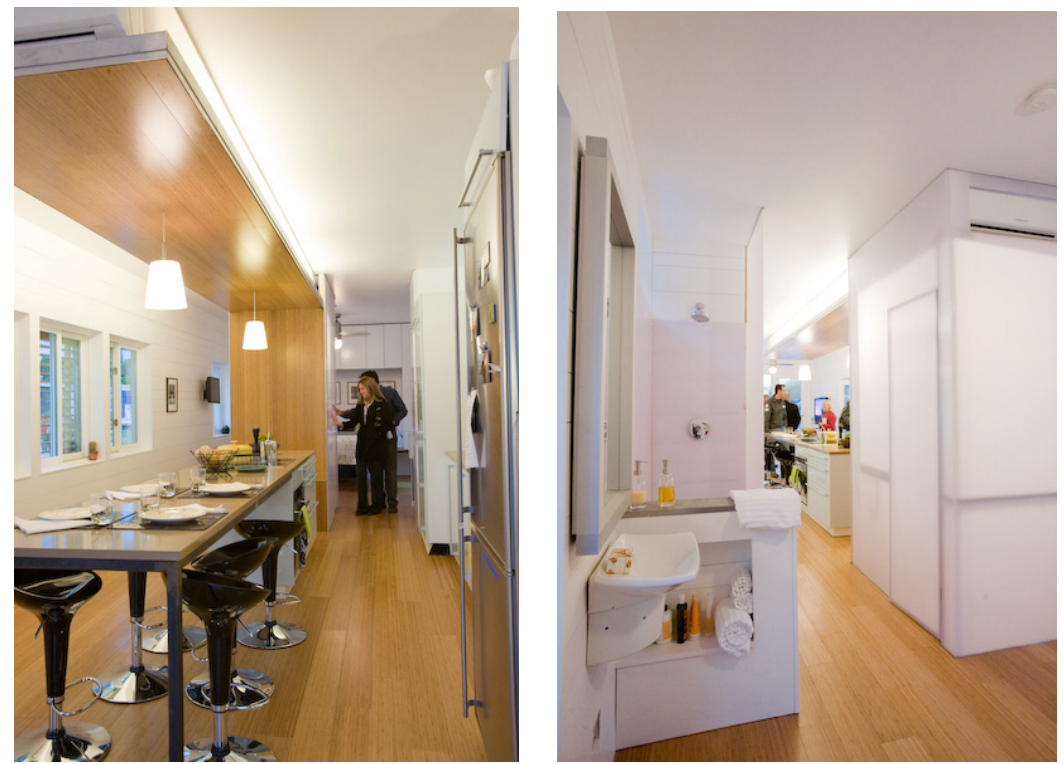

Figure 3: $\quad$ Interiors of the BLOOMhouse, (photo by Alex Miller).

The house was prefabricated by the student team headed by Alex Miller under the construction direction of Russell Krepart in a hangar at the old Mueller Airport in Austin. The house was shipped by truck to Washington, D.C. as a 
wide-load transport and unloaded on the National Mall using a system of hydraulic jacks. Onsite labor was reduced in this design scheme to the installation of the solar collectors and landscape decking. The energy-saving features of the house integrate strategically placed shading devices, cross ventilation, daylighting, advanced Energy Star appliances and equipment, fiberoptic and LED lighting prototypes, and the use of an evacuated tube solar hot water heating system with a hydronic floor heating system that discharges excess heat into a hot tub. The excess energy from the $6.6 \mathrm{~kW} \mathrm{PV} \mathrm{system} \mathrm{is} \mathrm{used} \mathrm{to}$ charge an electric vehicle with a goal of meeting the needs of commuters who put as many as 19,000 miles a year on their vehicles.

\section{Design and energy analysis}

The engineering student team led by Professor Atila Novoselac performed an energy analysis using several software packages. The software included, DOE2, PV-F-Chart and PV-DesignPros-S. The software was used to model window and shading devices, wall and ceiling structure and material properties, air infiltration/ventilation rates, thermal mass and building performance.

The results of the analysis showed that double-pane windows limited to $25 \%$ of total wall area and with a reflective coating, shading device (SHGC $=0.2)$ and exterior architectural shading devices on east and south facades optimizes performance.

Parametric analyses showed that for the house with the windows and shading devices that were specified for the BLOOMhouse that an increase of the R-value above a certain value did not provide any benefits. This optimum R-value was determined to be $25 \mathrm{~h} . \mathrm{ft}^{2 \circ} \mathrm{F} / \mathrm{Btu}$. This corresponds to a 6 " structural insulated panel.

The effect of infiltration and/or ventilation rate on energy use was also studied. For the selected windows, shadings devices, and R-value, for the BLOOMhouse the air exchange rate was set at .35 air changes per hour. In order to minimize the air quality problems for a house this airtight a mechanical energy recovery ventilation (ERV) system was added to assure adequate amounts of interior fresh air.

Because the BLOOMhouse needed to be lightweight, in order to be transported to the National Mall, thermal mass was reduced in the use of construction materials while relying on a solar hot water powered hydronic "warm floor" to achieve radiant heating during winter conditions.

Additional analysis proved that lower exterior surface absorption for walls affected annual energy consumption. Therefore light color exterior surfaces with an absorption index .8 to .4 were specified.

These energy conservation measures, coupled with energy star appliances and an energy-efficient lighting load of .5 W/sf, and a mini-split Heating, Ventilation and Cooling (HVAC) system, determined that the peak HVAC load would be less the $2 \mathrm{~kW}$ in order for the BLOOMhouse to meet the competition's strict comfort zone design requirements of $74^{\circ} \mathrm{F}$ and a relative humidity (RH) of $50 \%$. 

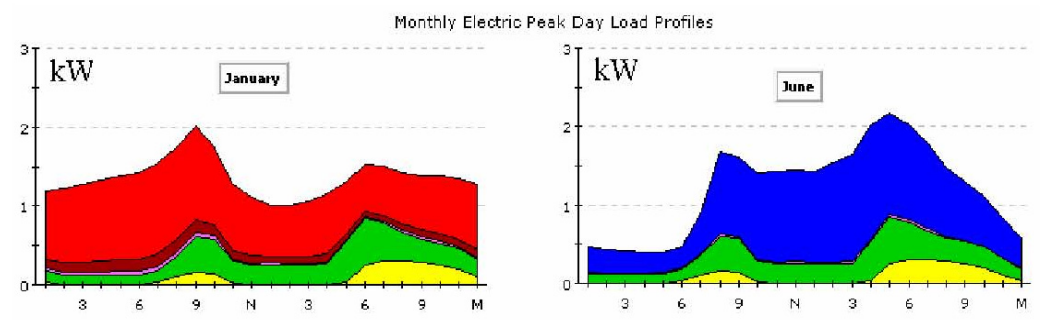

Figure 4: $\quad$ Energy load of the BLOOMhouse (chart by Atila Novoselac).
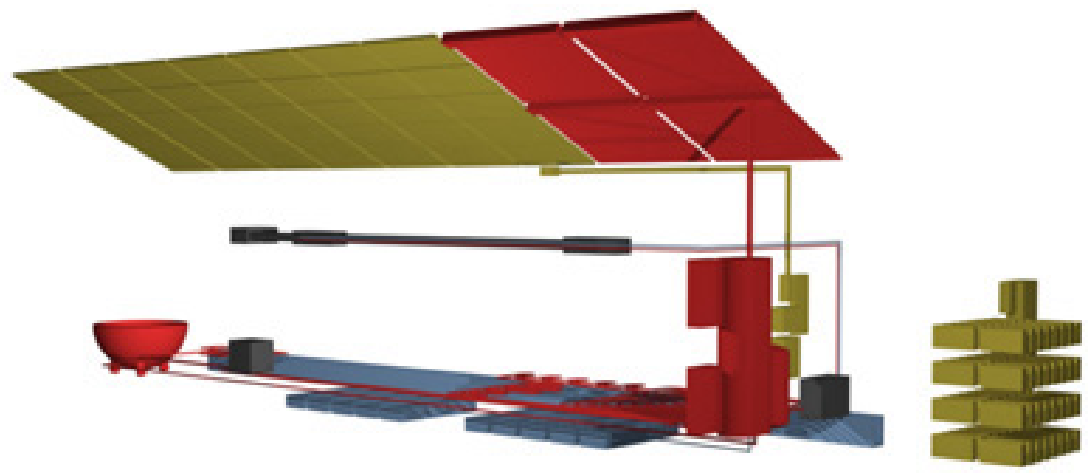

Figure 5: $\quad$ BLOOMhouse mechanical systems (diagram by Sam Covey).

\section{Solar hot water system}

Evacuated-tube solar collectors provide the energy for the water heating for the kitchen, bathroom, dishwasher, clothes washer and the hydronic floor heating system. This system requires two tanks (40 gallon and 120 gallon capacity) for hot water storage and a control system that regulates the energy flow in-between these two tanks. For Austin, Texas evacuated tubes positioned on the roof, with an area of $60 \mathrm{sf}$, provide enough energy to heat the domestic hot water needs during the year and provide additional energy for hydronic heating during the heating season. The annual savings of electrical energy attributed to the "warm floor" heating is $780 \mathrm{kWh}$ and total energy consumption for the solar is reduced from $7340 \mathrm{kWh}$ to $6560 \mathrm{kWh}$.

\section{Solar PV system}

Roof-mounted photovoltaic panels are oriented towards the south with a tilt angle of $18^{\circ}$. This low tilt angle was determined by the Solar Decathlon competition requirements, related to the height of the house. The PV system 
consists of 35 BP Solar- Saturn 7190 photovoltaic panels. The efficiency of the panels is $15.1 \%$ resulting in a maximum power output of $6.63 \mathrm{~kW}$. The photovoltaic panels convert light directly into electricity which is sent to a controller which distributes the energy between storage in a battery bank, used to charge the car, or used to run the loads of the house. The system is connected to four SMA SunnyBoy Inverters, which are used to convert the DC electric power from the photovoltaic array to AC power required to run household appliances. The battery bank was sized to store enough electricity for 5 consecutive "dark days".

\section{Conclusions}

In assessing the Solar Decathlon competition, as process, pedagogy, and product, it becomes clear that the challenges and possibilities of the Solar Decathlon are not solely engaged in questions of renewable energy. In fact, logistics, material assemblies, inhabitation, building code integration and education became the driving concerns that focused the project around the broader questions of collaboration and sustainability as an environmental, technical and social practice. These issues are critical to presenting the feasibility of solar energy technologies to the general public, and are closely inter-related. While there is no one solution, experience has proved that by blending design questions with logistics questions and performance questions with social questions, we ultimately turn an environmental challenge into environmental research which is based upon principles of collaboration - between a homeowner and the home, between a building and its environment, between ecology and economics.

The team's investigations suggest that progressive technologies offer solutions to the serious emerging challenges of energy efficiency and sustainable development and thereby become a strong design shaping force. These progressive technologies integrate photovoltaic systems; passive solar heating, solar-induced ventilation, daylighting, water use efficiency, regenerative waste management, smart energy management systems, and other low-entropy open building systems that contribute to "green" architecture. This study of building systems also includes the principles, conventions, standards, applications and restrictions associated with the manufacture and use of existing and emerging construction materials and assemblies and their effect on the environment. These technologies serve as catalysts for change.

\section{References}

[1] The 2002 University of Texas Solar Decathlon Team, Report on the 2002 Texas Solar D House, National Renewable Energy Lab, Washington D.C., 2003

[2] The 2005 University of Texas Solar Decathlon Team, Report on the 2005 Texas Solar D House, National Renewable Energy Lab, Washington D.C., 2005 
[3] The 2007 University of Texas Solar Decathlon Team, Report on the 2007 Texas Solar D House, National Renewable Energy Lab, Washington D.C., 2007

[4] Solar Decathlon, The 2005 International Competition of Solar Home Design, The Rahus Institute- Solar School House Publication, First Edition, Jan 2006

[5] Randall Stout and Michael Garrison, Building Envelope, National Council of Architectural Registration Boards, Washington D.C., 2004 